\title{
DEVELOPMENT OF AN ELECTRET MICROPHONE IN SILICON
}

\author{
A. J. SPRENKELS and R. A. GROOTHENGEL
}

Twente Technology Transfer, P.O. Bax 545, 7500 AM, Enschede (The Netherlands)

A. J. VERLOOP and P. BERGVELD

University of Twente, P.O. Box 217, 7500 AE, Enschede (The Netherlands)

\begin{abstract}
We describe a subminiature electret microphone, which has been realized in silicon using wafer processing techniques. The microphone consists of a rigid backplate fabricated in silicon and a $2.5 \mu \mathrm{m}$ thick metallized Mylar foil (PETP) acting as the diaphragm. Between the diaphragm and the backplate a $20 \mu \mathrm{m}$ thick air cavity and a $1.1 \mu \mathrm{m}$ thick charged $\mathrm{SiO}_{2}$ layer are present. The $\mathrm{SiO}_{2}$ layer is used as the electret and generates an electric field in the air gap. The electret has been changed to $300 \mathrm{~V}$ using a corona-charging set-up. The time constant of the charge decay amounts to more than 100 years at ambient laboratory conditions.

The microphone cartridge, which measures $3 \times 3 \times 0.3 \mathrm{~mm}$, shows an open-circuit sensitivity of about $2.5 \mathrm{mV} / \mu$ bar at $1 \mathrm{kHz}$.
\end{abstract}

Introduction

The application of photolithographic processes and micromachining in silicon for the construction of a subminiature microphone is rather new $[1,2]$.

The example given in Fig. 1 shows a microphone consisting of a silicon substrate with a $20 \mu \mathrm{m}$ thick air cavity and a $2.5 \mu \mathrm{m}$ thick metallized Mylar diaphragm. This diaphragm has been fixed to the backplate by means of a polymer via the holes $G$ through the backplate. The microphone contains a $1.1 \mu \mathrm{m}$ thick charged $\mathrm{SiO}_{2}$ layer (electret), a number of holes (A) to provide

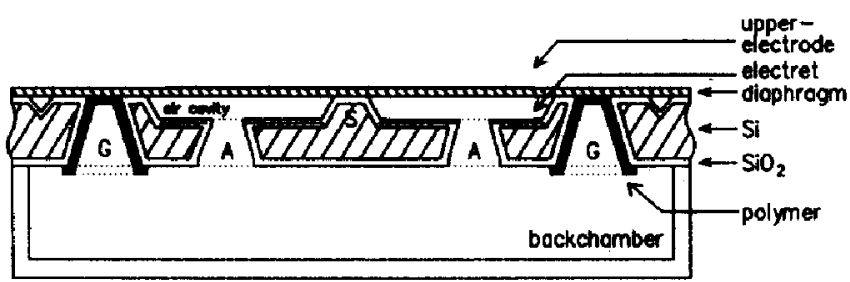

Fig. 1. A schematic cross-section of the silicon electret microphone. 
the necessary connection between the air cavity and the backchamber, and a diaphragm support (S) to prevent the collapse of the diaphragm as a result of electrostatic attraction. This attraction results from the charge in the $\mathrm{SiO}_{2}$ layer, which generates an electric field in the air gap.

The electret microphone may be considered as a capacitor that is permanently charged due to the presence of the electret between both capacitor plates, while one of the plates (the metallized diaphragm) is sensitive to sound. Assuming a zero initial tension in the diaphragm, the open-circuit microphone sensitivity $S_{0}$, expressed in $V / \mu b a r$, of a square diaphragm with side $2 a$, may be approximated by [2]:

$$
S_{0}=\frac{V_{\mathrm{f}} \epsilon_{\mathrm{f}}}{\left(s_{\mathrm{f}}+\epsilon_{\mathrm{f}} s_{\mathrm{a}}\right)} \frac{1}{\left[\frac{h^{3} E\left(1+1.6(w / h)^{2}\right.}{0.138 a^{4}}\right]+\left[\frac{P_{0}}{s_{0}}\right]}
$$

The first factor is the electrical sensitivity of the microphone cartridge. Here $V_{t}$ is the electret voltage, $s_{a}$ the zero-pressure air-gap space, $s_{t}$ the thickness and $\epsilon_{t}$ the relative dielectric constant of the electret material. The second factor (mechanical sensitivity) describes the two restoring forces acting on the diaphragm: the first due to the mechanical properties of the diaphragm, and the second due to the compression of the entire effective air volume of the backchamber. Here $h$ is the thickness, $E$ is Young's modulus and $w$ is the static centre deflection of the diaphragm as a result of the electrostatic force originating from the electret charge. $P_{0}$ is the atmospheric pressure and $s_{0}$ is the effective thickness of the backchamber [2].

Using this model, an open-circuit sensitivity of about $3 \mathrm{mV} / \mu$ bar can be calculated for a microphone with the following parameters: $s_{\mathrm{a}}=20 \mu \mathrm{m}$, $s_{\mathrm{f}}=1.1 \mu \mathrm{m}, V_{\mathrm{f}}=-300 \mathrm{~V}, E=5 \times 10^{9} \mathrm{~N} / \mathrm{m}^{2}, h=2.5 \mu \mathrm{m}, a=0.3 \mathrm{~mm}, s_{0}=$ $2 \mathrm{~mm}, w=4.5 \mu \mathrm{m}$ and $\epsilon_{\mathrm{f}}=3.9$.

\section{Microphone fabrication}

For the realization of the silicon backplate, we start with an n-type 5 - $10 \Omega \mathrm{cm}$ (100)-orientated oxidized silicon wafer. A $1 \mu \mathrm{m}$ thick oxide layer is used as a mask for the KOH solution that has been used as the anisotropic etchant (Fig. 2(a)). First the air cavities are etched to a depth of $20 \mu \mathrm{m}$. This is performed by patterning the $\mathrm{SiO}_{2}$ layer and subsequently etching the wafer in a $\mathrm{KOH}$ solution (Fig. 2(b)). After subsequent oxidation (Fig. 2(c)), both sides of the wafer are patterned and etched simultaneously using KOH. From the reverse side of the wafer two types of holes are etched through the wafer. One type (A) ends in the air cavity and forms the necessary connection between the air gap and the backchamber behind the backplate, as already shown in Fig. 1. The other type (G) is etched around the air cavity area, in order to attach the diaphragm to the backplate in a 
(o)

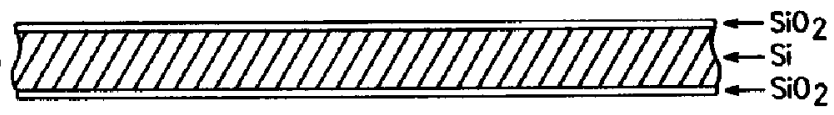

(b)

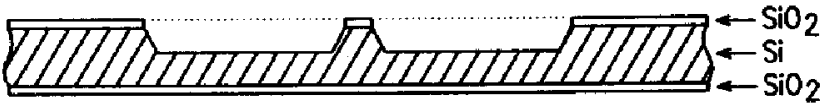

(c)

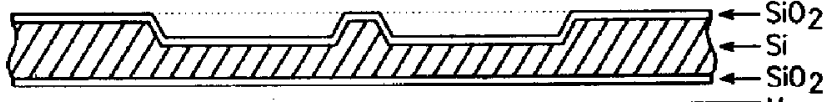

(d)

$\sqrt{2 / 1_{6}}$

Q7?

12177771

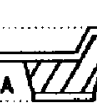

(e)

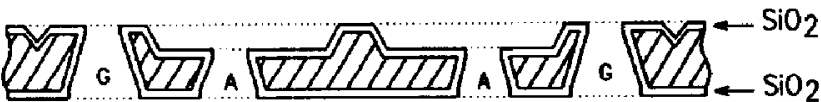

(1)
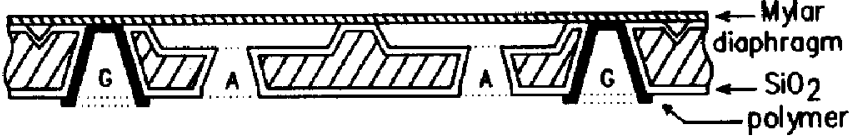

Fig. 2. Processing steps of the described silicon electret microphone.

later processing step. At the same time V-grooves are etched around the structures. This simplifies the dicing of the individual microphones after the processing has been completed. The result of this anisotropic etching process is shown in Fig. 2(d). After etching the remaining $\mathrm{SiO}_{2}$, the wafer is thermally oxidized again for about $3 \mathrm{~h}$ at $1150{ }^{\circ} \mathrm{C}$, resulting in a $1.1 \mu \mathrm{m}$ thick $\mathrm{SiO}_{2}$ layer on the entire wafer (Fig. 2(e)). Next the $\mathrm{SiO}_{2}$ surface is chemically treated in order to reduce the lateral surface conduction $[2,3]$. Subsequently the $\mathrm{SiO}_{2}$ layer is charged to $-300 \mathrm{~V}$ using a corona-charging method, which has proven to be an adequate method to charge a complete wafer. At this stage of the process the diaphragm has to be attached. This is done by fixing a $2.5 \mu \mathrm{m}$ thick Mylar foil on top of the complete wafer. The actual attachment results from spraying a polymer through the holes (G) around the air cavities. This method yields a strong attachment of the diaphragm on the backplate. The resulting cross section is shown in Fig. 2(f). After evaporating the upper electrode on top of the diaphragm, the wafer is diced, resulting in separate microphones.

\section{Experimental results}

The frequency response of the silicon microphones has been measured using a standard 'artificial voice' (B\&K 4219). The frequency range of our measurement set-up is limited from $100 \mathrm{~Hz}$ to about $15 \mathrm{kHz}$. The result is presented in Fig. 3. The sensitivity is about $2.5 \mathrm{mV} / \mu \mathrm{bar}$, which is in rather good agreement with the calculated value. The curve in Fig. 3 is a typical example of results for the five microphones that have been tested. None of the five microphones showed a discrepancy of more than 5\% relative to the given example. 


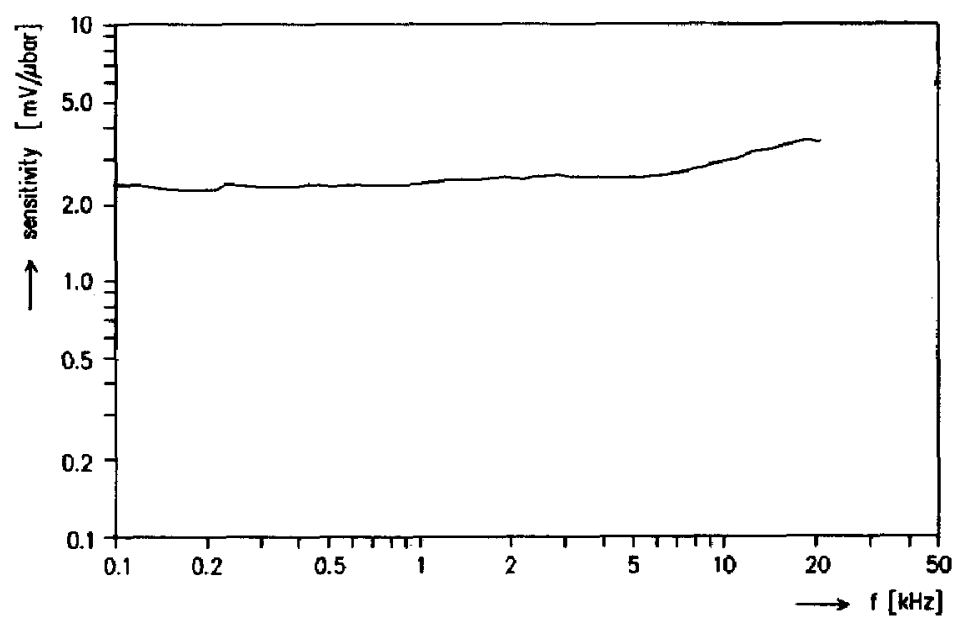

Fig. 3. The measured open-circuit frequency response of a prototype silicon electret microphone.

\section{Conclusions}

We have demonstrated that the use of photolithographic processes and anisotropic etching techniques can be succesfully employed in the realization of a subminiature electret microphone. In addition, it has been shown that $\mathrm{SiO}_{2}$ can be used as an excellent electret, provided that the lateral surface conduction has been reduced by a chemical surface modification.

\section{References}

1 D. Hohm, Subminiatur-Silizium-Kondensatormikrofon, Conf. Proc. DAGA'85, Stuttgart, F.R.G., 1985 , pp. $185-188$.

2 A. J. Sprenkels, A silicon subminiature electret microphone, Thesis, Twente University, 1988.

3 J. A. Voorthuyzen, K. Keskin and P. Bergveld, Investigations of the surface conductivity of silicon dioxide and methods to reduce it, Surface Sci., 187 (1987) $201-211$. 